\title{
THE PATTERN OF OVARIAN SECRETION OF OESTRADIOL AND OESTRONE DURING PREGNANCY AND THE POST-PARTUM PERIOD IN THE HAMSTER
}

\author{
H. S. JOSHI AND A. P. LABHSETWAR \\ The Worcester Foundation for Experimental Biology, \\ Shrewsbury, Massachusetts 01545, U.S.A. \\ (Received 15th April 1972, accepted 24th April 1972)
}

\begin{abstract}
Summary. A total of forty-nine samples of ovarian venous blood from pregnant hamsters was analysed by radioimmunoassay for oestradiol and oestrone. The secretion rate (ng/hr/ovary) and the concentration ( $\mathrm{ng} / \mathrm{ml}$ blood) of oestradiol were low on Day 1 of pregnancy, showed a significant rise before implantation on Day 3, and remained elevated on the day of implantation (Day 4) with no significant changes until after Day 9. Between Days 10 and 12 , the values rose sharply to peak levels $(P<0.01)$ which were followed by a significant $(P<0.05)$ decline during the last 3 days of gestation. The secretion of oestrone paralleled that of oestradiol. The secretion of both oestrogens was very low during the post-partum period.
\end{abstract}

The hamster has a gestation period of 16 days and ovaries are indispensable throughout pregnancy (Greenwald \& Rothchild, 1968). The corpus luteum is maintained in a functional state by a combination of FSH and prolactin, the latter apparently being secreted by the placenta in the second half of pregnancy (see Greenwald \& Rothchild, 1968). Implantation of blastocysts in hamsters occurs on Day 4 (Orsini, 1962) although ovarian oestrogen is not required for this purpose (Prasad, Orsini \& Meyer, 1960; Harper, Dowd \& Elliot, 1969). In the present study, the concentration and secretion rate of oestradiol and oestrone in the ovarian venous blood (OVB) was determined during pregnancy and the post-partum period. The choice of the OVB rather than the peripheral serum was largely dictated by a much higher concentration of steroids in the former tissue, thus minimizing the problems of blanks and the possible cross reaction of the adrenal steroids as has been observed in rats (Labhsetwar, 1972a).

Adult, sexually mature hamsters were maintained under controlled environmental conditions of light (from 06.00 to 18.00 hours) and temperature $\left(22^{\circ} \mathrm{C}\right)$ and caged with the fertile males on the night of pro-oestrus. The day on which spermatozoa were found in the vaginal smear was taken as Day 1 of pregnancy. Hamsters were anaesthetized with chloral hydrate $(7.5 \%$ solution, $5 \mathrm{ml} / \mathrm{kg}$, intraperitoneal) and prepared for ovarian vein cannulation as 
described by Eto, Masuda, Suzuki \& Hosi (1962) in rats. Ovarian vein blood was collected in a graduated tube kept on ice, usually for $15 \mathrm{~min}$, from forty-nine hamsters at various stages of pregnancy and during 1 to 4 days post partum. The samples were stored at $-20^{\circ} \mathrm{C}$ until assayed for oestrogens. The volume of blood collected varied from 0.3 to $2.3 \mathrm{ml} / 15 \mathrm{~min}$.

The blood samples were thawed and appropriate tracers were added for calculation of recoveries. The samples were extracted three times with three

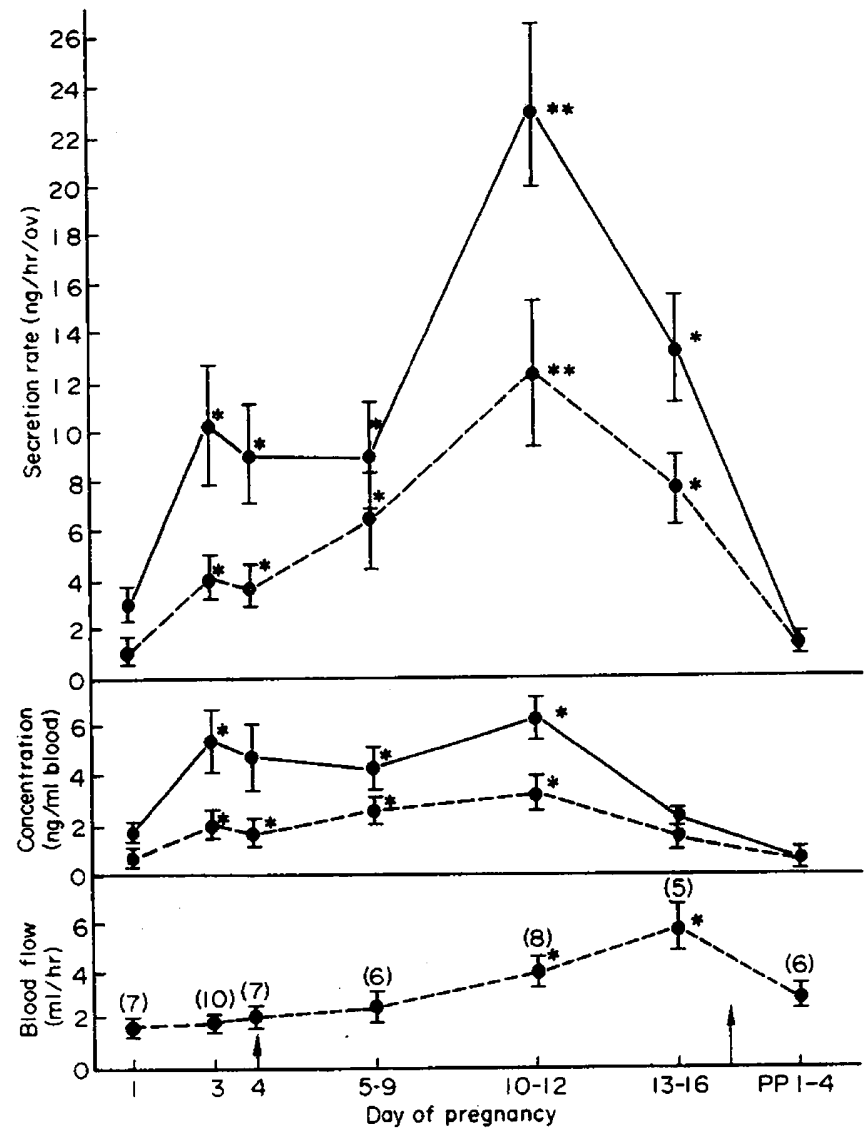

TEXT-FIG. 1. Blood flow rate (lower), concentration (middle) and secretion rate (upper) of oestradiol (- - and oestrone (- - ) in the ovarian venous blood during pregnancy and the post-partum period in the hamster. Each value represents mean $\pm S$.E. The number in parentheses in the lower figure indicates the number of samples in each group. The arrow at Day 4 denotes the day of implantation and that before the post-partum (PP) period, the day of parturition. ${ }^{*} P<0.05, * * P<0.01$ when compared with Day 1 .

volumes of a mixture of ethyl acetate:cyclohexane $(2: 1, \mathrm{v} / \mathrm{v})$. The extracts were fractionated on Celite microcolumns and fractions containing oestradiol and oestrone were analysed by radioimmunoassay as described by Abraham, Hopper, Tulchinsky, Swerdloff \& Odell (1971) and Nagai \& Longcope (1971). The mean recovery of oestradiol was $88.1 \%$ and that of oestrone was $68.9 \%$. The water blank for oestradiol was 5 to $19 \mathrm{pg}$, and for oestrone it was indistinguishable from zero. All values have been adjusted to $100 \%$ recovery and expressed either as concentration 
( $\mathrm{ng} / \mathrm{ml}$ blood) or secretion rate ( $\mathrm{ng} / \mathrm{hr} /$ ovary). In calculating the secretion rate, peripheral concentrations were ignored since, from the few samples assayed, they were assumed to be very low.

The concentration and secretion rate of both oestradiol and oestrone were low on Day 1 and rose on Day 3 before implantation (samples were collected between 12.30 and 19.00 hours) (Text-fig. 1). These data suggest occurrence of oestrogen rise before implantation in hamsters similar to that described in rats (Shaikh, 1971). The values remained high on the day of implantation, i.e. Day 4, and no significant fluctuations in the concentration, secretion rate or blood flow rate were observed until after Day 9. Between Days 10 and 12, the secretion rate of either steroid rose several-fold $(P<0.01)$ both because of an increased concentration and an augmented blood flow rate. This rise was followed by a significant $(P<0.01)$ decline in the secretion rate of both steroids during the last 3 days of gestation. The oestradiol concentration was low during the post-partum period $(P<0 \cdot 01)$. The concentration of oestrone also showed a significant rise during gestation (Text-fig. 1). The ratio of oestradiol level to oestrone was in favour of the former throughout pregnancy and approached unity during the post-partum period (Text-fig. 1).

Our results show that the ovary of the hamster secretes far more oestrogens than that of the rat (Yoshinaga, Hawkins \& Stocker, 1969; Shaikh, 1971). There was a significant rise in the oestrogen secretion preceding and coinciding with implantation followed by a sharp rise between Days 10 and 12 when the placenta apparently begins to secrete a part of the luteotrophic hormone complex-prolactin (Greenwald \& Rothchild, 1968). This rise also correlates well with a marked increase in the LH content of the pituitary, a surge in follicular growth and hypertrophy of the corpora lutea observed at this time of gestation (Greenwald, Keever \& Grady, 1967). The decline in the oestrogen secretion during the pre-partum period contrasts with a rise observed in rats (Yoshinaga et al., 1969; Shaikh, 1971), sheep (Challis, 1971) and, probably, in guineapigs (Challis, Heap \& Illingworth, 1971). Besides initiating parturition, the rise in oestrogen secretion may play a rôle in the post-partum ovulation which is known to occur in rats and guinea-pigs but not in hamsters (see Greenwald \& Rothchild, 1968); in sheep, the oestrogen rise may be involved in the induction of post-partum oestrus (Terrill, 1962). The positive feedback of oestrogen is an integral part of the train of events which precedes spontaneous ovulation in the oestrous cycle of rats (Labhsetwar, 1970), hamsters (Labhsetwar, 1972b) and, probably, in other species. Thus, our failure to observe an increase in the oestrogen secretion during the pre-partum period may be related to the lack of post-partum ovulation in this species. The other possibility is that the time of sampling OVB may have missed the rise.

The ovarian secretion of oestrogen was minimal during the post-partum period. This is probably due to the fact that the ovary of the post-partum hamster is exclusively composed of the interstitial and fibrous tissues totally lacking antral follicles and luteal tissue (Greenwald, 1965). This implies that antral follicles and/or corpora lutea are the major sources of oestrogens in this species.

We thank Dr L. Levy, Mrs B. Carr and Mr D. Watson for carrying out the 
steroid determinations. This study was supported by Contract No. CSD/2837 from the U.S. Agency for International Development.

\section{REFERENCES}

Abraham, G., Hopper, K., Tulchinsky, D., Swerdloff, R. \& Odell, W. (1971) Simultaneous measurement of plasma progesterone, 17-hydroxyprogesterone and oestradiol-17 $\beta$ by radioimmunoassay. Anal. Lett. 4, 325.

Challis, J. R. G. (1971) Sharp increase in free circulating oestrogens immediately before parturition in sheep. Nature, Lond. 229, 208.

Challis, J. R. G., Heap, R. \& Illingworth, D. V. (1971) Concentrations of oestrogen and progesterone in the plasma of nonpregnant, pregnant and lactating guinea-pigs. F. Endocr. 51, 333.

Eto, T., MAsuda, H., Suzukr, Y. \& Hosi, T. (1962) Progesterone and pregn-4-en-20 $\alpha$-ol-3-one in rat ovarian venous blood at different stages in the reproductive cycle. Jap. F. Anim. Reprod. 8, 34.

GreENWALd, G. S. (1965) Histologic transformation of the ovary of the lactating hamster. Endocrinology, 77, 644 .

Greenwald, G. S., KeEver, J. E. \& Grady, K. L. (1967) Ovarian morphology and pituitary Fsh and LH concentration in the pregnant and lactating hamster. Endocrinology, 80, 851 .

GREENWALD, G. S. \& RothCHILD, I. (1968) Formation and maintenance of corpora lutea in laboratory animals. F. Anim. Sci. 27, Suppl. 1, 139.

HARPER, M. J. K., Dowd, D. \& ElLIOTt, A. (1969) Implantation and embryonic development in the ovariectomized-adrenalectomized hamster. Biol. Reprod. 1, 253.

LABhsETWAR, A. P. (1970) The role of oestrogens in spontaneous ovulation: evidence for positive oestrogen feedback in the 4-day oestrous cycle. F. Endocr. 47, 481.

Labhsetwar, A. P. (1972a) Peripheral plasma levels of immunoreactive 'oestradiol' in rats during various reproductive states: adrenal contribution of immunoreactive material. F. Endocr. 52, 399.

LABHSETWAR, A. P. (1972b) The role of estrogens in spontaneous ovulation: evidence for positive feedback in hamsters. Endocrinology, 90, 941.

Nagal, N. \& Longcope, C. (1971) Estradiol-17 $\beta$ and estrone: studies on their binding to rabbit uterine cytosol and their concentration in plasma. Steroids, 17, 631.

Orsins, M. W. (1962) Study of ovo-implantation in the hamster, rat, mouse, guinea-pig and rabbit in cleared uterine tracts. F. Reprod. Fert. 3, 288.

Prasad, M. R. N., Orsint, W. \& Meyer, R. K. (1960) Nidation in progesterone-treated, estrogendeficient hamsters, Mesocricetus auratus (Waterhouse). Proc. Soc. exp. Biol. Med. 104, 48.

ShaIKH, A. A. (1971) Estrone and estradiol levels in the ovarian venous blood from rats during the estrous cycle and pregnancy. Biol. Reprod. 5, 297.

Terrill, C. E. (1962) The reproduction of sheep. In: Reproduction in Farm Animals, p. 244. Ed. E. S. E. Hafez. Lea \& Febiger, Philadelphia.

Yoshinaga, K., Hawkins, R. \& StockeR, J. (1969) Estrogen secretion by the rat ovary in vivo during the estrous cycle and pregnancy. Endocrinology, 85, 103. 